This item was submitted to Loughborough's Research Repository by the author.

Items in Figshare are protected by copyright, with all rights reserved, unless otherwise indicated.

\title{
Vendor opportunism in IT outsourcing: a TCE and social capital perspective
}

\section{PLEASE CITE THE PUBLISHED VERSION}

http://dx.doi.org/10.1057/jit.2015.3

\section{PUBLISHER}

(c) Palgrave Macmillan

\section{VERSION}

AM (Accepted Manuscript)

\section{PUBLISHER STATEMENT}

This work is made available according to the conditions of the Creative Commons Attribution-NonCommercialNoDerivatives 4.0 International (CC BY-NC-ND 4.0) licence. Full details of this licence are available at: https://creativecommons.org/licenses/by-nc-nd/4.0/

\section{LICENCE}

CC BY-NC-ND 4.0

\section{REPOSITORY RECORD}

Liouliu, Eleni, and Angelika Zimmermann. 2019. "Vendor Opportunism in IT Outsourcing: A TCE and Social Capital Perspective". figshare. https://hdl.handle.net/2134/17282. 


\title{
Vendor Opportunism in IT Outsourcing: A TCE and Social Capital Perspective
}

\author{
Eleni Lioliou \\ School of Business and Economics \\ University of Loughborough, UK \\ \& \\ Angelika Zimmermann \\ School of Business and Economics \\ University of Loughborough, UK
}

\author{
Corresponding author: \\ Dr. Eleni Lioliou \\ University of Loughborough \\ School of Business and Economics \\ Loughborough, Leicestershire \\ LE11 3TU \\ United Kingdom \\ e.lioliou@lboro.ac.uk \\ Tel: +44 (0)1509 263171 \\ Fax: +44 (0)1509 222701
}




\title{
Vendor Opportunism in IT Outsourcing:
}

\section{A TCE and Social Capital Perspective}

\begin{abstract}
Academic researchers have attributed significant attention to the drivers of opportunistic behavior, yet our understanding of how opportunistic behavior can be mitigated remains relatively fragmented. Our investigation will focus on the social context and more specifically on the role of social capital in the deterrence of opportunistic behavior. Based on two qualitative case studies in the financial sector, we will illustrate how the structural, cognitive, and relational dimensions of social capital can reduce internal and behavioral uncertainty between the outsourcing partners, thereby facilitating the mitigation of opportunistic behavior. In our study we combine the theory of transaction costs with social capital theory and demonstrate how they can usefully complement each other to enhance our understanding of mechanisms that can deter opportunistic behavior.
\end{abstract}

Keywords: Vendor opportunism, Transaction costs, Social capital, IT outsourcing, Case study

\section{INTRODUCTION}

IT outsourcing has emerged as an important tool for enabling organizations around the world to enhance their competitiveness by gaining access to the distinctive expertise and technological competencies of external suppliers. The result of this trend is a significant upsurge in the outsourcing of information technology. The combined global market revenues for IT and business process outsourcing for 2010 were estimated to exceed \$US 237 billion and were set to rise 8-12\% per annum between 2011 and 2014 (Willcocks et al., 2011). 
While the growth of outsourcing has been impressive, there is still a lot to be learnt with regards to the management of external service provision. A significant amount of research has been devoted to outsourcing decisions and in particular the type of activities to be outsourced (Dibbern et al., 2008; Møller-Larsen et al., 2012; Stringfellow et al., 2008). While this stream of studies has yielded significant insights for the effectiveness of outsourcing strategies, an important amount of research is increasingly concerned with the ongoing governance of outsourcing arrangements (i.e. Mani et al., 2012; Goo et al., 2009; Gopal \& Koka, 2012; Gulati \& Nickerson, 2008) .

Both commercial and academic publications have recognized outsourcing governance as a key mechanism for the achievement of desirable outsourcing outcomes, but also for the mitigation of outsourcing risks related to the engagement of opportunistic behavior (Equaterra, 2010; Lacity et al., 2010; Mercer, 2010). Opportunistic behavior in particular has been widely acknowledged as a central concern with outsourcing activities (McIvor, 2008).

Academic researchers have attributed significant attention to the drivers of opportunistic behavior (Lumineau \& Quelin, 2011). From a transaction costs economics (TCE) perspective, a number of studies indicated asset specificity (and in particular investments that are relationship specific) and uncertainty as the primary drivers of opportunistic behavior (Chen \& Bharadwaj, 2009; Goo et al., 2009; Barthelemy \& Quelin, 2006; Ang \& Cummings, 1997). While this stream of research has generated significant insights, the very own phenomenon of opportunism, particularly with regards to its behavioral dimensions, has not be adequately addressed (Lacity et al., 2011; Rindfleisch et al., 2010; Macher \& Richman, 2008; Wathne \& Heide, 2000). Moreover, a number of TCE studies have taken into account certain facets of uncertainty while ignoring others (Tiwana \& Bush, 2007; Aubert et al., 2004; Poppo \& Zenger, 2002) or neglecting the role of uncertainty all together (Lumineau \& Quelin, 2011; De Vita et al., 2010 Jap \& Anderson, 2003; Grober \& 
Cheon, et al.), focusing solely on the construct of asset specificity. More generally, research on TCE has been criticized for neglecting the social context of transactions (Zazac \& Olsen, 1993; Granovetter, 1985).

These are the departure points for our study. Our investigation will focus on the social context, and, more specifically, on the role of social capital in the deterrence of opportunistic behavior. Up to now, social capital theory has not been applied to the study of opportunistic behavior in business transactions, but we will demonstrate that it is a useful complement to TCE in addressing this issue. Based on two qualitative case studies in the financial sector, we will illustrate how the structural, cognitive, and relational dimensions of social capital can reduce uncertainty between the outsourcing partners, thereby facilitating the mitigation of opportunistic behavior. In this manner, weaddress the need for an examination of the behavioral dimensions of opportunism, the role of uncertainty in driving opportunistic behavior, and the social context of outsourcing transactions.

\section{LITERATURE REVIEW}

\section{Vendor opportunism and IT outsourcing}

A central premise of the theory of transaction cost economics is the assumption of opportunism. In particular, this assumption holds that decision makers, given the opportunity, are acting out of self-interest. Williamson (1985:47) defined opportunism as: 'a lack of honesty or candor in transaction, to include self-interest seeking with guile...More generally, opportunism refers to the incomplete or distorted disclosure of information, especially to calculated efforts to mislead, distort, disguise, obfuscate, or otherwise confuse'. Opportunistic behavior of vendors in IT outsourcing arrangements may take many forms, for example failing to fulfill promises and obligations, withholding or distorting information regarding the venture or reducing quality in the delivery of products or services. 
The intense focus of TCE on the malicious side of human nature, where individuals "will not reliably self-enforce promises but will defect from the letter and spirit of an agreement when it suits their purposes” (Williamson, 1985), has led a large stream of research to excessively criticize the theory. In particular, there have been strong judgments that such Machiavelian view on human nature can generate insights that are "dangerous" (Perrow, 1986) and "bad for practice” (Ghosal and Moran, 1996).

Evidently, Williamson did not maintain that all individuals are going to behave opportunistically in all circumstances. On the contrary, he suggested individuals to be "engaged in business as usual, with little or no thought to opportunism, most of the time" (Williamson, 1993). He further clarified that "although it is unnecessary to assume that all human agents are identically opportunistic, much less continuously opportunistic, it is truly utopian to presume unfailing stewardship” (Williamson, 1998). He therefore maintained that a thorough examination of the hazards of opportunism is essential for the mitigation of these hazards (Williamson, 1998).

Based on a transaction costs economic perspective therefore, a significant amount of research has been concerned with contractual attributes and safeguards that can limit the potential for opportunistic behavior and ensure that the terms of transactions will be enforceable. In this vein of research, it was suggested that a significant level of detail and accuracy is needed at the contractual level so that the possibility for the engagement of opportunistic behavior by the vendor becomes mitigated (Parkhe, 1993; Saunders, et al., 1997; Aubert et al., 2004). Furthermore, contracts must be constructed in such a way so that the client avoids over-dependence on the vendor (Lacity \& Willcocks, 2009).

From a relational perspective, another stream of research suggested that relational governance mechanisms can be also used for the mitigation of opportunistic behavior by the vendor. This stream of research suggested that while an organization may have the potential 
to behave opportunistically against its partner, it may not do so. Mechanisms regulating a partner's behavior include trust (Lee et al., 2008; Barthelemy, 2003; Sahay et al., 2003; Uzzi, 1996) commitment (Mohr \& Spekman, 1994), communication (Kern \& Willcocks, 2002; Sahay et al., 2003; Tompkins et al., 2006) and power-control (Klein, 2000; Lacity \& Willcocks, 2009). By acknowledging that such relational mechanisms can mitigate opportunistic behavior, this research modifies TCE theory's original tenet that transaction partners will behave opportunistically if they have the opportunity to do so (Williamson, 1985).

In our study, we are going to take a new perspective on the behavioral aspects of vendor opportunism in IT outsourcing. In particular, we are going to examine how social capital mechanisms, in the form of the cognitive, structural and relational dimension of social capital reduce uncertainty around the transaction and therefore mitigate opportunistic behavior. To the best of our knowledge, this is the first study that aims to complement the theory of transaction costs with the theory of social capital in the study of opportunistic behavior.

\section{$\underline{\text { Transaction cost economics theory }}$}

The theory of transaction cost economics has been widely used in the study of sourcing decisions. A number of TCE studies have focused on the role of asset specificity in transaction costs and the respective 'make' or 'buy' decision. The rationale for doing this has been the recognition of 'asset specificity' by Williamson (1985) as the most important dimension that explains costs of the transaction, more so than the TCE elements of 'uncertainty' and transaction 'frequency'. More specifically, Williamson (1981: 1546) has suggested that 'a considerable amount of explanatory power turns on the asset specificity 
variable, with neither uncertainty nor frequency -alone or in combination- leading to hierarchical governance’.

While asset specificity is a key determinant of transaction costs, since it is directly related to the object of the exchange, we argue that an analysis that downplays the role of the uncertainty or transaction frequency is going to be unnecessarily limited. Our paper singles out the uncertainty component and examines how it depends on social capital, whilst transaction frequency and its relation to social capital is beyond the scope of our study. This choice was driven by our data, namely our respondent's primary emphasis on the uncertainty component.

The theory of transaction costs has been highly criticized for not paying enough attention to the social embeddedness of transactions (Ghosal \& Moran, 1996; Granovetter, 1985; Uzzi, 1996; Zazac \& Olsen, 1993). In particular, this stream of research has critiqued the prevalence of economic performance as a driver of exchange behavior, which is a basic tenet of TCE (Borgatti \& Foster, 2003). Researchers have tried to combine TCE with other organizational theories in order to address this limitation. As examples, Artz and Brush (2000) combined the theories of transaction costs and relational exchange and found that relational norms decrease transaction costs. Similarly, Nyaga et al. (2010) combined the theories of transaction costs and relational exchange to study the economic and relational factors that drive satisfaction and performance. Bahli and Rivard (2013) following Ouchi (1980) integrated the concept of ‘clan mechanisms’ of governance into Williamson’s TCE framework.

We argue that focusing on 'uncertainty factors' can illuminate significant social factors surrounding the transaction and affecting the outsourcing outcome. Accordingly, we expect that the theory of social capital can usefully complement the theory of transaction costs 
and illustrate how mechanisms of social capital can mitigate uncertainty and therefore opportunistic behavior between the outsourcing partners.

In our analysis we will distinguish between different types of uncertainty that impact transaction costs. Uncertainty is generated by phenomena that are hard to anticipate and, consequently, hard to specify in the contract. As Klein (1989:256) suggested 'It appears that uncertainty is too broad a concept and that different facets of it lead to both a desire for flexibility and a motivation to reduce transaction costs'.

Taking into account the broadness of uncertainty as a concept, we observe that a number of TCE studies have operationalized uncertainty in a relatively constrained manner, taking into account certain facets of uncertainty while ignoring others or neglecting the role of uncertainty all together (De Vita et al.,et al., 2010; Thouin, et al.,et al., 2009; Gooroochurn \& Hanley, 2007). Williamson (1985) himself did not give a very detailed definition of uncertainty. Based on the work of Koopmans (1957), he identified three classes of uncertainty. The primary class of uncertainty is 'state contingent'. The secondary class arises 'from lack of communication, that is from one decision maker having no way of finding out the concurrent decisions and plans made by others'. The third class of uncertainty, Williamson called 'behavioral uncertainty'. On behavioral uncertainty he noted that 'the secondary uncertainty ... is of a rather innocent or non-strategic kind. There is a lack of timely communication, but no reference is made to strategic non-disclosure, disguise, or distortion of information. Such strategic features are unavoidably present, however, when parties are joined in a condition of bilateral dependency. A third class of uncertainty- namely, behavioral (or binary) uncertainty- is thus usefully recognized’ (Williamson, 1985).

Since Williamson's conceptualization of uncertainty has not been regarded as particularly concrete to operationalize, further work on transaction costs has distinguished between environmental, internal and behavioral types of uncertainty. In this frame, 
environmental uncertainty corresponds to Williamson's conceptualization of primary uncertainty; internal uncertainty resembles to Williamson's conceptualization of secondary uncertainty; and behavioral uncertainty constitutes Williamson's third type of uncertainty. In our analysis therefore, we will take an integrated perspective and examine all three types of uncertainty.

In particular, regarding environmental uncertainty (commonly defined as the difficulty to foresee changes in the external environment because of exogenous forces), we will initially adopt the categorization made by Walker and Weber (1984). The authors extended the basic TCE framework developed by Williamson and identified two types of environmental uncertainty: volume and technological. Volume uncertainty refers to the inability of predicting the necessary demand from a certain type of a product or service due to exogenous factors. Technological uncertainty, on the other hand, refers to an inability to foresee and follow technological changes. Furthermore, in our analysis we will include the availability of alternative suppliers as a source of environmental uncertainty (Cannon \& Perrault, 1999) as well as regulatory pressures (Miranda \& Kim, 2006).

As far as internal uncertainty is concerned, we will initially focus on the ability of a firm to clarify its requirements regarding what is the exact kind of service or product it needs. Furthermore, following Aubert et al. (2004), we will examine the level of professionalization in the IT department. We also follow Karimi-Alaghehband et al. (2011) and Lacity et al. (2011) and take into account measurement difficulties in the assessment of uncertainty. We classify these issues as types of internal uncertainty.

As far as behavioral uncertainty is concerned, this is related to difficulties in predicting the actions of the exchange party, in the light of the potential for opportunistic behavior. A number of TCE studies (for example Rindfleisch \& Heide, 1997; Geyskens et al., 2006) relate behavioral uncertainty to the difficulty of measuring the performance of the 
vendor. Geyskens et al. (2006:521) very specifically mention that 'the effect of behavioral uncertainty is a performance evaluation problem- that is, difficulty in ascertaining ex post whether contractual compliance has taken place'. However, coining behavioral uncertainty to difficulties in measurement departs from the core of TCE logic (Karimi-Alaghehband et al., 2011), and we therefore focus our assessment of behavioral uncertainty on possibilities for opportunistic behavior that the supplier may engage in.

\section{$\underline{\text { Social capital }}$}

Social capital can be understood as 'the goodwill that is engendered by the fabric of social relations and that can be mobilized to facilitate action' (Adler \& Kwon, 2002: 17). Researchers have focused on social relations of individuals as well as groups, and on their internal social ties (with members of their own social group), or external social ties (with other groups, their members, or individuals outside the group). These social ties generate resources, which is captured in Nahapiet and Ghoshal's (1998) prominent definition of social capital as the 'resources embedded within, available through, and derived from an individual's or social unit's network of relationships (Nahapiet \& Ghoshal, 1998: 243). We use Nahapiet and Ghoshal's definition to investigate the resources that a vendor and a client firm gain from their relationship within an outsourcing arrangement. More specifically, we will argue that the social ties between vendor and client create resources that enable these partners to decrease uncertainty and thereby reduce the risk of opportunistic behavior.

Social capital can yield several benefits. Many empirical studies have demonstrated the relation of social capital with performance, either of individuals, groups, projects, or organizations (see Payne et al., 2011: 499). Adler and Kwon (2002) focus on more specific benefits and classify information, influence, control and power, and solidarity as the most important ones. To illustrate, social ties provide easier access to information and facilitate 
knowledge sharing (e.g. Inkpen \& Tsang, 2005; Van den Hoof et al., 2004; Reagans \& Evily, 2003). They are also a source of power, for example through obligations from other actors within the network (Coleman, 1988) or relationships with influential actors in the network. Moreover, strong social norms and beliefs lead to solidarity within a social network, because they encourage compliance with a group’s rules (Adler and Kwon; 2002: 29). This reduces the need for formal controls (Adler and Kwon; 2002: 29). We will argue that such solidarity will reduce the uncertainty of other network members' behavior, and will thereby mitigate the risk of opportunistic behavior.

The concept of social capital has been applied to a wide range of social settings, but, to our knowledge, not to the study of opportunistic behavior during business transactions. As mentioned above, research on relational governance has highlighted the importance on certain relationship aspects such as trust, commitment, and communication for mitigating the risk of opportunistic behavior, but has not examined them through the (more comprehensive) social capital lens. Moreover, a few researchers use the social capital lens within the IT outsourcing context, however without examining opportunistic behavior. These papers demonstrate the importance of social capital between outsourcing partners for their knowledge transfer ability and motivation (Rottman, 2008; Zimmermann and Ravishankar, 2014).

Several other researchers examine the function of certain relationship aspects, which are part of social capital, within outsourcing relationships (see Zimmermann, 2011: 68, for a review), but again without attention to opportunistic behavior. More specifically, there is evidence that on-site visits, frequent communication, and a shared understanding of tasks are fundamental to knowledge transfer and success in IT outsourcing collaborations (e.g. Dibbern et al., 2008; Subsingha et al., 2012). In the same vein, effective formal and informal communication between outsourcing partners (Herbsleb \& Mockus, 2003; Cataldo \& Herbsleb, 2008) as well as trust (Lee et al., 2008; Westner \& Strahringer, 2010) are well 
known preconditions of IT outsourcing success. On a more general level, it has been observed that strong relationships are particularly hard to achieve, but at the same time particularly important in virtual collaborations, which includes outsourcing partnerships (Cummings, 2011; Zahedia et al., 2010, Zimmermann, 2011).

Social capital theory provides a distinction between different dimensions of social capital, which helps us to identify how specific aspects of relationships function to reduce certain types of uncertainty in the transactions between client and vendor firm, and thereby help to mitigate the risk of opportunistic behavior. Nahapiet and Ghoshal (1998) differentiate between the structural, cognitive, and relational dimension of social capital.

The structural dimension refers to the overall pattern and configuration of connections between actors - i.e. 'who you reach and how you reach them' (Nahapiet \& Ghoshal, 1998: 244). This includes the presence or absence of ties, their strength, as well as their patterns, reflected in the shape of communication and interaction between actors. We assume that the structural dimension cannot directly affect the levels of uncertainty in a partnership, but is likely to affect it indirectly, by shaping the relational and dimensions, which we describe later on.

The cognitive dimension of social capital refers to the resources within relationships that provide shared representations, interpretations and systems of meanings (Nahapiet \& Ghoshal, 1998, p. 244). These can be part of a shared vision and culture (e.g. Inkpen \& Tsang, 2005), which again act as a bonding mechanism and shared frame of reference. The cognitive dimension of social capital is likely to be associated with internal uncertainty, because the absence of a shared frame of reference will make it hard for partner firms to achieve a shared understanding of requirements for products or services. By contrast, the cognitive dimension of social capital does not have any apparent direct effect on environmental or behavioral uncertainty. 
The relational dimension of social capital refers to assets created and leveraged through personal relationships (Nahapiet \& Ghoshal, 1998). Important facets of the relational dimension include trust and trustworthiness, norms and sanctions, obligations and expectations, and identity and identification (Nahapiet \& Ghoshal, 1998). Amongst these, trust is likely to be particularly important in counteracting behavioral uncertainty during a business transaction. Newell and Swan (2000: 1293) note that trust 'is about dealing with uncertainty and risk', thus stating the link between the relational dimension of social capital and uncertainty in an explicit manner. It is easier for network members to anticipate each other's behavior if they trust that other network members will keep their promises and will not pursue hidden agendas. Research on virtual collaborations has also highlighted that trust is particularly important for overcoming the uncertainties about remote colleagues' intentions and behavior, which are intensified by spatial, organizational, and cultural boundaries (Hsu et al., 2007; Zimmermann, 2011: 66). In the context of offshore outsourcing relationships, Kelly and Noonan (2008) emphasize that trust in offshore partners' ability, benevolence, and integrity reduce onshore partners' anxieties and increased their psychological security. We do, by contrast, not see any obvious links between trust and external or internal uncertainty.

With regard to the other parts of the relational dimension, we note that shared norms, and behavioral norms in particular, will make it easier for partners to anticipate each other's behavior, thus reducing behavioral uncertainty. Expectations and obligations, in turn, can counteract both internal uncertainty (in terms of clarity of required service) and behavioral uncertainty, if the transaction partners' expectations and perceptions of obligations are congruent. Furthermore, 'identification' is the condition where values or standards of the individual merge with those of a group, and this creates collective goals and aspirations. It is apparent again that this may create greater certainty about the behavior of the other transaction partner. Hence, with regard to the relational dimension of social capital, the effects 
on behavioral uncertainty are particularly apparent, even though they have not been investigated as such.

It should be emphasized that the three dimensions of social capital are interrelated. Shared identity, as part of the relational dimension, tends to go hand in hand with the shared representations and meanings that are part of the cognitive dimension of social capital (Nahapiet \& Goshal, 1998: 251. This implies that shared identity has an indirect effect on internal uncertainty, through its connection with shared representations. Shared representions, in turn, is likely to have an indirect association with behavioral uncertainty, through their link with shared identity. The structural dimension, in turn, underscores both the cognitive and the relational dimension of social capital. When interactions in a social network are more frequent and ties are closer, members of the network will have a chance to develop a better shared understanding and shared vision (cognitive dimension), and they will be able to develop stronger trust and shared identity (relational dimension). Even though the structural dimension is not likely to affect uncertainty in a direct manner, it will therefore affect internal and behavioral uncertainty indirectly, by determining the other two dimensions of social capital.

Following on from our considerations on opportunistic behavior, uncertainty and social capital, we explore the following research question:

What roles do the cognitive, relational and structural dimensions of social capital play in the reduction of environmental, internal, and behavioral uncertainty, and therefore the mitigation of opportunistic behavior in an outsourcing context? We will now outline our research methods before presenting and discussing the findings of our inquiry.

\section{RESEARCH METHODOLOGY}

Our research question calls for a qualitative case study research method. We examine the role of social capital in the reduction of uncertainty, which incorporates the questions of how and 
why social capital plays a role in this matter. A particular strength of qualitative case studies lies in their use for exploring such how and why questions, because they enable us to gain an understanding of the nature and complexity of the processes taking place (Benbasat et al., 1987). Our case study method thus yielded an in-depth explanation of how and why the different dimensions of social capital were connected with certain types of uncertainty. Qualitative case studies are further suitable for revealing complex social phenomena in relation to their real life context (Benbasat et al., 1987; Yin, 2009), allowing us to provide a rich description of social capital dimensions and uncertainty in certain company contexts.

Our study combines strong deductive and inductive elements (see Eisenhardt, 1989; Kirsch, 2004). On the one hand, our inquiry is guided by the extant theories of TCE and social capital, and by our theoretical considerations of how social capital may affect uncertainty and therefore the mitigation of opportunistic behavior in an outsourcing context. On the other hand, the study is to significant extents exploratory, because the functioning of social capital in uncertainty reduction has not been described or hypothesized before. Qualitative methods are particularly useful for exploring such under-researched matters, because they enable us to surface and understand unknown phenomena, and to demonstrate in depth how processes such as social capital and uncertainty are related to each other.

Our investigation was focused on the financial services industry. This sector is now widely perceived as the biggest consumer of IT outsourcing (Computer Weekly, 2013; Rawlinson, 2011) and we therefore regarded the selection of case studies within the financial services industry very typical in outsourcing. With regards to the outsourcing relationships under investigation, we examined arrangements that were of significance to the organization (i.e. a relationship with an important vendor) and had developed over some time. In such relationships, we would expect to be better able to investigate social capital and its impact. In particular, the first contract we examined was between a major Dutch organization in the 
financial-insurance sector (here named LION) and its supplier, an American organization that had a branch in the Netherlands (here named FDL). The contract included the development, support and maintenance of software applications. A large part of the outsourced work was performed in India. We conducted interviews with 12 participants during the period of January 2010, resulting in 11 sessions, as two of the participants were interviewed at the same time. Table 1 provides an overview of the research participants from LION and FDL.

- Insert Table 1 about here -

The second contract we investigated was between a global investment bank (here named GIB) and its Indian supplier (here named PV). The contract included the support and maintenance of applications that were of relatively low strategic importance to the bank. The project was named 'X-RAY'. We carried out interviews with 14 participants during the period of October 2009 to April 2010. Three interviewees were identified as key informants and interviewed multiple times (see Table 2), resulting in overall 25 interview sessions. The following table provides an overview of the research participants from GIB and PV.

- Insert Table 2 about here -

The interviews were semi-structured and our questions were open-ended (please see the appendix for our guiding list of questions). In most of the interviews only one researcher (the first author of this paper) was present, however during the interviews with the more senior management, another researcher (an expert in the field of outsourcing) joined in the interview. We further conducted follow-up interviews (face to face) where we felt we needed further clarifications in order to draw our conclusions. 
We used multiple data collection methods in order to provide a stronger substantiation of our theoretical constructs (Eisenhardt, 1989) and in addition to the interviews we viewed the outsourcing contracts under investigation, as well as documents on the outsourcing practices that the client and supplier organizations have been following. Having the chance to view these documents enabled us to gain more profound insights into internal uncertainty, particularly in terms of contract monitoring and level of professionalization within the IT departments. The evidence gained from these documents complemented the interview insights.

We chose to speak to managers who were involved in the outsourcing contracts under investigation, including operational managers, senior managers and directors who were knowledgeable about the relationship between their organization and the outsourcing partner. We included different management levels to gain a richer insight into the project under investigation and the development of the social capital between the two organizations. We tried to improve the validity of our findings by gathering insights both from the suppliers' and the client side. All interviews lasted for approximately one hour. The interviews were transcribed, coded and analyzed using Atlas software.

Our data analysis followed an iterative process of comparison between emergent findings with pre-existing concepts (see Eisenhardt, 1989; Kirsch, 2004). Due to our prior knowledge of TCE and social capital theory, our interviews gave us the initial idea of exploring the role of social capital in reducing uncertainty and opportunistic behavior. Our subsequent data analysis then allowed us to identify particular elements of uncertainty and social capital in the context of the case studies, and to describe specific links between these elements as presented by our respondents. When comparing these links with the relevant concepts in the TCE and social capital literatures, we established that the links were also plausible form a theoretical point of view. Accordingly, the coding of our data followed a 
procedure of template analysis (King, 2004) which was guided by the theories of TCE and social capital. In particular, we distinguished between the environmental, internal and behavioral types of uncertainty, as suggested by TCE, and we further distinguished between the cognitive, structural and relational dimensions of social capital. Based on our respondents' reports, we created codes for several elements of each different type of uncertainty and each dimension of social capital, which corresponded to elements described in the TCE and social capital literature. However, our respondents did not mention all elements of uncertainty and social capital that have been described in the literature. The main codes (13 overall) and illustrative quotes are provided in the appendix. Using these codes, we analyzed our data and followed a largely inductive approach to establish the links between our primary constructs.

The data was coded by the first author, and the results of the coding process were critically considered by both authors. To ensure a rigorous and valid interpretation of the data, we conducted many iterations when analyzing our evidence. Our intention was to 'understand the whole' by constantly revising it in 'view of the reinterpretation of the parts' (Myers, 1994). On this basis, we re-visited our interview transcripts and other documents several times during our analysis.

\section{THE LION - FDL CASE STUDY}

LION is a global financial institution offering a variety of products and services ranging from banking and insurance to asset management. It employs about 115,000 people and serves private, corporate and institutional clients in more than 50 countries. In 2006, the savings and loans division of LION Netherlands initiated a major outsourcing agreement. The agreement was signed with FDL, an organization that LION had already been co-operating with. FDL is a leading outsourcing provider specializing in the financial services industry. The company has a global presence and serves more than 60 countries. The contract was on application 
development, support and maintenance. The cost model appeared to be very efficient, as $70 \%$ of the labor was offshored to India, namely in Bangalore and Chennai and 30\% was based in Amsterdam. The offshored service was delivered by an Indian supplier which was an FDL company.

In their co-operation, the two organizations went through a 'get-to-know' period, where they faced various challenges that will be illustrated further on. Their venture had overall progressed in a satisfactory manner for both sides. LION seemed to have chosen the right supplier for the services it was seeking to outsource.

\section{Uncertainty around the LION contract}

\section{Environmental uncertainty}

LION was facing significant challenges in defining the volume of services it needed on the savings and loans systems development, support and maintenance. A major reason is that financial markets are highly unpredictable and that the demand for certain products and services changes rapidly. This volatility in the market environment is a significant driver for outsourcing within the financial services industry, particularly in information technology related products and business processes. As RP3 (LION Business manager) indicated: 'In an organization like ours, if you only develop for your own organization you need people to do that of course and you have them on your payroll. And there is times when they do not have anything to do and there is times when they have too much to do. There is never a smooth line in the work. An outsourcing vendor has more flexibility in putting the right people, at the right time, in the right company'.

Nevertheless, the financial industry went through a period of recession during 2008 and a lot of institutions in the sector, including LION, incurred significant losses. The financial stretch that LION had been going through as a result of the economic crisis in 2008 
made it compulsory for the firm to cut into its cost structure and reduce investments on systems development. Back then, LION negotiated with FDL to change their outsourcing cost model. The two organizations had a transparent discussion on the salary and compensation rates of the onshore and offshore workforce and decided that the most efficient way to go forward would be the reduction of the number of Indian employees. It appears however, that LION was still under pressure to reduce the volume of services outsourced to FDL on the savings and loans area. The disadvantage for LION was that reducing the size of the contract was most likely going to increase the pricing.

Research participants did not appear to be particularly concerned with issues of technological uncertainty in the area of the savings and loans products. The research participants within LION were, however, concerned about the future of the venture with FDL. FDL is an American company and LION is its major customer in the Netherlands. The problem was that the volumes LION needed from FDL in the Netherlands were declining as a result of the financial crisis. For this reason, some of the research participants within LION explained their fear that FDL might decide at some point to 'pull the plug' in the Netherlands. LION was therefore also looking at other suppliers. It appears however that a major challenge for LION was to identify a technically competent supplier that would also have experience with the Dutch regulatory environment.

\section{Internal uncertainty}

Within the LION organization there were a lot of issues stemming from requirements uncertainty that increased the transaction costs with FDL. According to the research participants, LION had a difficulty in translating its business requirements into systems requirements, but also in identifying the exact scope of projects. ''Furthermore, LION was very often changing its requirements, which inhibited the effective co-ordination of processes with the offshore team. RP2 (LION lawyer) explained: 'After the assessment of services you 
are supposed to have an idea of the scope... but this is never the case within LION, because scope can change until you have signed the contract and after... So one of the big issues with any contract is that you need fixed requirements. If you know that they are hard to fix, like the LION case, you need a very firm change process and you have to stick to that'. While these issues were important and were causing disturbances in the execution of operations, it appears that the two organizations put the right processes in place in order to handle 'requests for change’ relatively smoothly.

Furthermore, it appears that within LION, the level of professionalization within the IT department was not particularly strong. According to our interviewees, the communication lines between different disciplines of the organization did not operate effectively. The size of LION made it additionally challenging to organize the flow of information which made the execution of work harder.

In relation to the assessment of the performance of the vendor, it appears that LION was not facing any issues. The assessment of the service levels and the overall methodology against which the supplier's performance would be assessed was clearly established by the contract between the two organizations. LION and FDL seemed to have very explicit governance processes set up and according to the research participants, there were not any penalties or too many issues of serious escalations.

\section{Behavioral uncertainty}

LION and FDL had a long history of co-operation before signing the outsourcing arrangement. For this reason, LION had a good idea of FDL's capabilities and its way of conducting business, making FDL a reliable supplier. The prior history between the two firms provided LION with significant indications regarding the predictability of the vendor's behavior. FDL had convinced LION in relation to its trustworthiness, its skill set and its ability to perform. On this basis, the prior history between the two firms created high 
behavioral certainty, which mitigated the possibility that the FDL would behave opportunistically.

Furthermore, it appears that FDL valued LION as a customer very highly. LION is one of the top institutions in the financial sector and thus it added to its suppliers' reputation, including FDL. For this reason, it is reasonable to assume that FDL would want to keep LION satisfied as a client.

\section{$\underline{\text { Social capital }}$}

\section{Structural dimension}

Middle and senior management of LION visited the FDL site in India frequently and vice versa. At the working level, employees communicated via e-mail, phone, and teleconference, often on a daily basis. Employees from the supplier's side flew to the Netherlands quite often in order to discuss and address issues with the LION employees. The structural dimension of social capital between the partners was thus characterized by close and frequent interactions.

At the same time, a boundary spanner (RP9, contract manager from FDL) seemed to play a key bridging role in the communication and alignment of understanding between the two parties. Having significant knowledge within the business of LION (regarding processes, requirements, priorities, objectives) he often played the role of the liaison between the two organizations.

Over time, the two outsourcing partners strengthened their ties through increased interaction and communication. In particular, the two parties maintained high levels of continuous communication in order to clarify the objectives of their arrangement, explain the expectations and obligations of each party and ensure effective service delivery. Through this, the structural dimension of social capital, in terms of pattern of connections, helped to shape the cognitive and relational dimensions of social capital. 


\section{Cognitive dimension}

With respect to cognitive social capital, there were initially some issues related to the partners' shared representations of their work practices and objectives. While LION and FDL had a supplier-client relationship before signing their outsourcing arrangement, there was still a period during which the two organizations were getting familiarized with each other's operations, processes and objectives. RP3 (LION Business manager) illustrated: 'At the beginning you start off by looking at each other, searching for ways to work together, challenging each other, questioning why the supplier cannot be cheaper or cannot work faster and so on.... I have been in a few meetings between LION and FDL back then which were tough meetings, because we did not know how the other person or the other company worked and we had different expectations...' Furthermore, as mentioned before, the role of the boundary spanner (RP9, contract manager from FDL) had been critical in the alignment of business between the two parties. For example RP8 (LION Service manager) explicitly mentioned that RP9's 'understanding' and 'knowledge' enabled him to generate dependable views and take appropriate actions: 'RP9 came from LION and thus he knows very well our business and processes. He is also very good in giving announcements for new projects and rough estimations. He is able to do this because he knows our processes and he knows what is possible in the FDL architecture... So in a case of escalation when we call RP9, he understands the priority of it and he will try to do everything he can to deal with it...'.

Language barriers were also reported as a major challenge for arriving at shared mental representations and interpretation of requirements. For example, RP11 (Consultant from FDL) noted that understanding the LION requirements was in some instances particularly difficult: 'The thing is that Dutch people, while they are nice and helpful, they have a tendency to translate the Dutch language to English and they always have their own Dutch words in their text. Understanding the requirements has been a big challenge for us in 
many instances'. Similarly, RP7 (LION senior manager) noted: 'There is a significant language barrier because we are not native English and the people in India are not native English speakers either, so sometimes you really have to search for what both parties mean when they say something'.

Visiting the supplier's offices in India (mentioned above as part of the structural dimension of social capital) was proved to be a very good way of bringing the employees together and gaining a better shared understanding of each other's work practices. RP3 (LION Business manager) noted: 'I had the privilege to travel to India, where I spent a week at their offices in Bangalore and Chennai. I went there first because I was very interested to see how work is carried out there, what it looks like. But second of all ... to really meet the people that you are mailing with and that you are talking to. And to have a clear understanding of what we are doing. So I think that was a very, a very good thing to experience'.

Our interviewees mentioned that the on-going communication (which we mentioned as part of the structural dimension), lead to an exchange of ideas and integration of knowledge between the two parties, and was therefore very important for partners to gain competence in addressing issues, evaluating their alternatives, and improving the decision making process. In this manner, they had developed shared interpretations of how to collaborate. RP12 (Program manager from FDL) described this as a learning process which had led to significant improvements in the collaboration between the Indian team, the onshore team and LION: 'In each project, we have learned lessons. ... Every fortnight we have a working practices improvement meeting with LION. Maybe for their part they have some new things which could have been done in a better way. We are constantly looking for improvement opportunities'.

As part of their initial difficulties in developing shared representations, interpretations and meaning systems, the partners had also not developed a clear shared vision in the early 
stages of their collaboration. RP3 (LION Business manager) brought an example where LION realized that FDL did not have a good understanding of its aspirations and objectives: 'We had a program integrating Postbank and LION Bank and at a certain time, while we thought that FDL knew why we were doing the project, what our goals where, what our timelines where, what we expected from them, we realized that this was not the case. While we thought we had communicated that in a very good way... we recognized that we needed to go and tell them what the program was about.... We did spend some time telling our story, answering questions, explaining why we were doing this program'.

A number of interviewees commented on cultural issues between the on-site and the offshore team. Members of the Dutch site perceived the Indian team to be less proactive than LION would have liked them to be. A number of interviewees within LION commented on this issue. RP8 (LION service manager) noted that, to his frustration, although the Indian people had good technical competencies, they did not exploit them in order to come back with a new proposal for LION: 'The Indian people are really on the working floor, so they can hear what the dynamic is... they could use that more to enlarge their own contracts. They are not very good at seeing opportunities and work these opportunities out for themselves to come back with a concrete proposal to us... There has never been an instance that they will say 'Hey, I think this is going wrong in your organization and we could offer this kind of service to you'... They are only good in just doing what we ask them'. 


\section{Relational dimension ${ }^{1}$}

With regard to the relational dimension of social capital, respondents placed particular emphasis on the high level of trust between the partners. LION chose to work with FDL because they were confident that FDL was a technically competent organization. LION sought to work with a 'low-risk', rather than a 'low-cost' outsourcing partner and therefore the trustworthiness of the service provider was a priority during the supplier selection process. This indicates strong competence-based trust (see for example Newell \& Swan, 2000) towards the vendor. In the words of RP10 (Account manager from FDL): 'We made it very clear to LION that we are very trustworthy... the other suppliers were by far the cheapest in terms of cost savings, but we were by far the lowest risk because we had the skill set and we had a track record with LION... This is what convinced LION to work with us'.

Moreover, participants in FDL clearly demonstrated a 'partnership' style of behavior when the needs of LION changed and the outsourcing arrangement needed to be revisited. LION, on the other hand, did not impose sanctions on FDL as a result of its underperformance during the integration project of Postbank and LION. The two firms worked together so that the requirements by LION were clearly communicated to FDL. This style of collaboration indicates high levels of companion trust (Newell \& Swan, 2000), referring to the belief that the other partner will be open and honest, and not do harm to other members of the network. The partners' behavior also points to their belief that the partner would be committed to deliver according to the requirements of the contract, which describes commitment trust (Newell \& Swan, 2000).

\footnotetext{
${ }^{1}$ With regard to the relational dimension of social capital, our respondents provided detailed accounts of trust and communication norms, but placed far less emphasis on the other parts of the relational dimension that are theoretically relevant for uncertainty reduction, namely 'obligations and expectations' or 'identity and identification'. This is likely to be due to the prominent role of trust and communication norms in the relationships, but also due to the less tangible, more abstract nature of 'obligations' and 'identity'. To do justice to our respondents' perceptions, we do not include them in our analysis, both in the LION-FDL as well as the GIB-PV case study.
} 
The high levels of trust can be traced back to the history of the collaboration. FDL was already doing a big part of the work that would be outsourced and had demonstrated a satisfactory competence in that work. A number of interviewees within LION commented that the prior good relationship between the two organizations, together with the satisfactory performance that FDL had been demonstrating constituted the major reasons why FDL won the contract. As RP3 (LION Business manager) commented: 'LION selected FDL to offer services based on responses provided by FDL to an RFP for the outsourcing of the applications for savings and based on past experiences in working with FDL'.

Face to face discussions during visits (described as part of the structural dimension of social capital) served to develop and maintain the trust between the two organizations. According to our LION respondents, the frequent visits from their supplier also constituted a good prove that FDL was a reliable organization.

Furthermore, the partners had developed strong shared norms of communicating in an open and transparent manner. RP1 (LION director) gave an example where the two companies worked very transparently on their agreement and demonstrated a partnership-style of behavior. He explained that LION was facing a big pressure to reduce its costs and thus it was forced to cut down on systems development and subsequently on the hours they would need from FDL. He suggested that the two companies had a very honest discussion on the salaries of the Indian and Dutch employees (including the cost of lay-offs) and they changed the cost-structure of the contract accordingly: 'Last year in 2008 until the middle of this year, like all banks, we had a huge cost reduction... one of the decisions we took was to seriously cut back on systems development, which of course reduced the number of hours we would need from FDL. They came back to us and said 'The India part is not a problem. In India you simply say to your people going to the office that you do not need them anymore and that you will give them a call whenever you need them again. So there is an immediate ability to 
reduce labour costs'... In the Netherlands the story is different because you first have to pay them to leave and then again if you would like to hire them again... so it is an expensive process. So they said 'Isn't it a good idea if you think that this cost pressure is a temporary thing to do the cost reduction in India? Of course the mix of employees based offshore versus the ones based onshore will be different, resulting in an increase on the average price per hour... but in total, the business case is better... That is under the condition, you as a customer, think this is a temporary thing'. We discussed this together and decided to keep the people in the Netherlands... And this is a very transparent way - and I think an example of partnership- where they said 'lets openly discuss the choices we have'...'.

\section{THE GIB - PV CASE STUDY}

GIB is a major European bank with operations in more than 75 countries spread across Europe, USA and the Asia-Pacific. It has more than 80,000 employees and provides a range of investment and financial services to individuals, corporations and institutional clients. PV is a major IT company that provides a variety of products and services including software, $\mathrm{BPO}$ and infrastructure management services and it is one of the primary vendors of GIB. PV is based in India, it employs about 55,000 people and is one of the country's largest IT services exporters. Our investigation was focused on the 'X-RAY' project, which was on the development, support and maintenance of applications that were of relatively lower strategic importance for the bank.

GIB and PV have a long standing business relationship. In particular, GIB created an organization called GIB Software in 1999, which was an offshore captive. This captive had been taken over by PV in 2004, and a number of the captive employees became PV employees. Some of the interpersonal relationships between the employees of the two organizations had therefore been long-lasting and strong. 


\section{Uncertainty around the GIB contract}

\section{Environmental Uncertainty}

GIB interviewees emphasized that environmental uncertainty was a major concern for all firms operating in the financial sector. As an example, RP14 (GIB director of risk) mentioned that: 'the financial industry is probably the most fast-pacing industry and we have to be dynamic as an organization, we have to keep up with the changes'. Changes in the market, customers' preferences and needs as well as technology shifts are some of the primary challenges that financial firms have to cope with constantly. Furthermore, the bank was particularly sensitive to regulatory requirements, and thus in the contract there were several contractual clauses that requested the supplier to adhere to any regulatory changes. As an example, the service levels of the project needed to be amended from time to time in the light of any changing regulatory practices or any new industry wide procedures. The bank created the 'global sourcing division' which was working in conjunction with the legal department in order to make sure that any demand revisions were within the terms of the contract. Our interviewees did not mention facing issues with regards to the availability of suppliers.

\section{Internal uncertainty}

The year 2005 constituted a milestone in GIB's approach to IT outsourcing because the company decided to enhance its governance processes and make them more rigid. By that time, the firm had recognized that having a strong governance mechanism in operation was of critical importance for keeping a tight control of its processes and realizing the benefits of IT outsourcing. On this basis, GIB started to work extensively on its IT outsourcing governance mechanisms and processes in 2005. By 2007, the firm managed to establish a strong IT outsourcing governance apparatus that has only been fine-tuned since then. In this sense, the level of professionalization within the IT department of GIB has been particularly strong after 2007. 
GIB had a very integrated approach to contract monitoring and was trying to make sure that this function was taking place on a cross division basis. Furthermore, GIB was very effective in setting down initial requirements, estimating what processes could be influenced through IT outsourcing and how. On this basis, internal uncertainty in GIB appeared to be pretty low.

Similar to the LION-FDL case, GIB also had no particular difficulties in measuring the performance of the vendor, and interviewees did not mention any significant disagreements with the vendor related to performance achieved. While PV did not always fully adhere to the SLAs, the end users were overall satisfied with service delivery. RP24 (PV Global account manager) further illustrated the strong governance in place between GIB and PV by emphasizing on the rigorous processes they follow: 'All these governance meetings are documented in terms of what is discussed, what is agreed and then we track certain things. We go back next week and say what did we decide?... What have we achieved?... Then we say that we have achieved this, we haven't achieved this, why we haven't achieved this and what else we need to do in order to achieve what was agree... There is a fairly rigorous process of governance'.

\section{Behavioral uncertainty}

Our respondents within GIB identified PV as a 'reliable' vendor in terms of capabilities as well as commitment. This made the vendor's behavior predictable, and rendered the perceived chances of opportunistic behavior low. As an example, RP 14 noted (GIB director of risk) 'GIB maintained a long relationship with PV... We know PV very well... the people, the management.... We knew that support and maintenance of applications was something that they are good at'. While there had been some turbulent times in the relationship of the two organizations, the two firms had established numerous outsourcing projects and PV was recognized as a strategic vendor to GIB. This long history of co-operation appeared to be an 
important factor in decreasing behavioral uncertainty, and thereby limiting the possibility for vendor opportunism. Our interviewees mentioned that there were interpersonal relationships between the two organizations that lasted over 20 years.

Furthermore, PV appeared to be very highly interested in keeping GIB satisfied, not least because it was its number one customer. RP25 (PV X-RAY Global transformation manager) illustrated the significance of GIB as a customer to PV: 'We are dependent on the business and their support for so much of our work because that's the basis of our revenues. It's the basis for our, you know, promoting to other customers, also in terms of learning and so on'.

\section{$\underline{\text { Social capital }}$}

\section{Structural dimension}

The two organizations had been doing business with each other for a long time. As already been mentioned, GIB's captive operation was taken over by PV in 2004 and a lot of captive employees became PV employees. Some of the interpersonal relationships between GIB and PV had developed over the previous 20 years. On this basis, the two firms maintained a spirit of relative closeness. PV was considered to be one of the most important vendors of GIB. PV had undertaken many projects within GIB and the contracts between the two organizations were often being renewed.

Furthermore, the two organizations had very clear patterns of connections and communication lines which were documented. Organizational members maintained frequent communication, and according to our interviewees, they felt quite close to their counterparts. On-going communications was seen as important in clearing out the objectives of the arrangement, as well as the obligations and expectations of each party. Furthermore, in 
situations that required significant attention, members of GIB would fly over to India and vice-versa, in order to ensure that the arrangement progressed in line with the objectives.

\section{Cognitive dimension}

Because the two organizations had been collaborating for many years and some PV employees had been part of the former GIB offshore captive, cognitive social capital between the two organizations was highly developed. RP24 (PV Global account manager) noted that PV had a very good understanding of GIB's systems, and according to him this was a very important reason why PV won the contract over its competitors and also a significant factor for the effective development of the venture. In his words 'We have a very long relationship with them. We knew our understanding was much better than some of our competitors. We knew a lot of these applications... we had actually created some of these applications. There was a good understanding of the technology and the applications.... These were important reasons why $[\mathrm{PV}]$ were chosen and we were capable to perform well'.

The shared understanding of the client's technology was also important when SLA definitions were vague. The SLA created the risk that it did not safe-guard all of the customer's interests. Some areas were easy to measure (e.g. downtime of a system), yet some areas were more vague (e.g. quality of code). Regarding the interpretation of the performance of the vendor, it could be secondary whether an SLA had been met. It was the user's expectations that needed to be fulfilled. On this basis, if an SLA had been met, however the users were not satisfied with the service, the end result was dissatisfaction with the supplier. Conversely, if users were satisfied with the service, even if an SLA had not been met, there would be no dissatisfaction with the supplier. Through their good understanding of the client firm's system, PV was better able to fulfil user requirements regardless of the SLA specifications. 
The two organizations had also been working regularly towards the alignment of their objectives and visions. Strong governance processes were there to support the exchange of views, ideas and align the visions between the two organizations. On this issue, RP23 (PV Head of integrated services delivery) noted: 'Alignment of visions... This is what we do in our quarterly steering committee meetings. This consists of two parts. In the first part, we discuss how we have done in the past. In the second part we discuss what our vision of our account is... At the same time, GIB is sharing with us at which direction they are moving and what is expected from us. We constantly align our objectives and goals to make sure that both are working towards achieving those objectives’.

According to our respondents, there were some on-going cultural issues between PV and GIB, but it appeared that these remained at a reasonable level. RP21 (GIB X-RAY product manager) illustrated that in a global business environment, cultural differences were always going to be present, but organizations needed to be flexible and accommodating: 'Cultural issues should not be a big problem... but you have to realize, you have to understand that there is a difference in the culture. As long as you understand that, then I do not see that as a big problem.... In that global business environment you should be able to be working with people with different cultures anyway... you should be accommodating'.

As in the LION-FDL case, however, our GIB respondents observed some cultural obstacles. They mentioned that while PV was capable of delivering according to the expected standards, they did not demonstrate a proactive attitude. In the words of RP16 (GIB Investment Banking IT Sourcing and Vendor Management of IT portfolio): 'We still have a cultural issue.... Indian culture is pretty much made of 'yes... yes...' rather than 'why'... The proactive thinking of Indian developers is not comparable at all with some of the vendors in Russia. In Russia they are thinking of 'how can I make that better, what is a better alternative' etc... Regarding PV however (and other Indian vendors of ours) if you tell them 
$A, B$ and $C .$. they will do $A, B, C$. They may do $A, B, D$ because they did not get it right. If you are wrong in asking for $A, B, C$ but $A, B$, E... they will never offer you $A, B, E$... even if they know that A, B, C is not the best solution'. He acknowledged, however, that GIB did currently not pay adequately enough to obtain the best PV talent. He mentioned that Indian vendors, including PV, would try to allocate their best talent to the most attractive projects at the most attractive rates.

\section{Relational dimension}

In this case study, respondents focussed again on trust and communication norms, far more than on other parts of the relational dimension. The two organizations had built significant amount of trust over the years. RP25 (PV X-RAY Global transformation manager) elaborated on the way that PV tried to demonstrate its willingness to co-operate with GIB and how a climate of trust had been created: 'We wanted to show them that we would go to any extent to ensure that their expectations from us would be met... We put a lot of effort into understanding what the business wanted from GIB IT and in effect what GIB IT wanted from us'. In addition to organizational trust, interpersonal trust at the individual level was also very important in the view of our respondents. RP24 (PV Global account manager) emphasized: 'After all, people work with people... There is a lot of good in the organizations working together for a long time... There is a feeling of comfort.'.

Trust had also been established because people within the two organizations felt that their counterparts were being supportive. As an example, RP26 (PV X-RAY European program manager) illustrated his own experience: 'On a personal note, speaking with some of the GIB managers they have said to me 'If you ever need any help, even though we are expecting not to be involved, come over and shout if there is problem. It might be something that we are aware of or something that we have a point of view on'... So that is very good for the venture... that means that we are building the relationship with the GIB management.... 
Because you need to be able to say 'I need your help in this'... or 'I do not know, I really do not know the answer to that and thus I need your support'... If I am comfortable to be able to go over and do that, then they will feel the same kind of trust...'.

In addition to trusting relationships at the project level, the two organizations had strong relationships at the executive level. According to our interviewees, these relationships between senior managers also contributed to the maintenance of a good working spirit between the two organizations.

As in the LION-FDL case, the norms of communication between the organizations were characterized by openness and transparency. Our interviewees explained they could be open and honest with their counterparts. The words of RP13 (GIB Vendor decisions/Relationship management) are very revealing, in that the vendor was open in the confrontation of problematic situations: 'They have acknowledged that they had a fault in some cases, they have revealed things to us that we did not know they were wrong, but that was good.... I was quite amazed actually at some of the things they told us voluntarily... but I like it'.

\section{DISCUSSION}

\section{The role of social capital in uncertainty reduction}

Our results imply that social capital played an important role in reducing uncertainty and thereby mitigating opportunistic behavior in the outsourcing partnerships. The precise linkages are presented in Figure 1.

- $\quad$ Insert Figure 1 about here - 
The LION-FDL as well as the GIB-PV outsourcing projects faced high levels of environmental uncertainty. In LION, the volume of services needed from the service provider within the savings and loans area had been changing with the unpredictable fluctuations of the financial markets, and had declined as a result of the financial crisis of 2008. Respondents at GIB, in turn, saw major challenges in the changes of the market, customers' preferences, and technology. The service providers in both case studies under investigation could have exploited these uncertain circumstances and demanded that the client firms fulfilled their commitments according to the initial contract, whether the clients made actual use of the service or not. In other words, environmental uncertainty could have encouraged opportunistic behavior. However, the social capital between the client and the vendor organizations reduced the levels of internal and behavioral uncertainty (as discussed later on) and therefore mitigated the possibility for such a scenario.

Internal uncertainty was low in the GIB-PV case but high in the LION-FLD case. GIB and their vendor had defined precise formal governance mechanisms. They were also effective in defining initial requirements and facilitating and monitoring the contract. The low levels of internal uncertainty within GIB limited the potential for PV to behave opportunistically. LION, in contrast, had difficulty in translating its business needs to systems requirements and identifying the scope of projects. The information flow within LION was also not effective, and the communication lines between different organizational divisions were blurred. This internal uncertainty within LION could have been exploited by FDL, yielding opportunistic behavior. However, instead of this, the two organizations worked further on the development of their cognitive social capital (shared representations and vision) and aligned their goals, objectives and supporting processes. It therefore appears that building social capital, and in this instance the cultivation of their cognitive social capital, mitigated 
the levels of internal uncertainty between the two organizations (see link between cognitive dimension and internal uncertainty in Figure 1).

At the beginning of their co-operation, LION and FDL had different visions and their expectations had not been communicated properly. Their mutual understanding regarding the goals of their arrangements was limited, and therefore the basis for an effective co-operation was constrained. During the process of building structural social capital in terms of appropriate information sharing processes and points of communication, the two organizations came closer and started to understand each other better. Through this, the cognitive dimension of social capital was built (see link between structural dimension and cognitive dimension in Figure 1), and internal uncertainty was decreased (see link between cognitive dimension and internal uncertainty in Figure 1). This reduction in internal uncertainty provided security to FDL with regards to the engagement of opportunistic behavior on behalf of the vendor.

Regarding the GIB and PV case, cognitive social capital in terms of GIB's and PV's shared understanding of user requirements served as a complement to formal governance mechanisms when these did not fully represent the user requirements, thus decreasing internal uncertainty (see link between cognitive dimension and internal uncertainty in Figure 1). Based on their shared understanding, GIB did not impose any penalties even when the vendor did not adhere to the SLAs, as long as the satisfaction of users was significant. Conversely, when the vendor did adhere to the SLAs, but the satisfaction of users was low, PV acknowledged that it had to work with GIB and find ways and processes to improve the users' satisfaction. Cognitive capital had in this case been built through the close and frequent interactions over the long time of the collaboration, which had allowed the vendor to gain a thorough understanding of GIB's systems and develop shared objective. In this sense, the structural dimension of social capital was again the basis for developing the cognitive 
dimension of social capital (see link between structural dimension and cognitive dimension in Figure 1).

In addressing internal uncertainty, LION and FDL also developed shared communication norms as they worked out their information sharing in an open and honest way (relational dimension of social capital). This provided them with better knowledge of the operations of each other, the business requirements of LION and the calculation model by FDL, demonstrating a link between the relational and cognitive dimension of social capital (see Figure 1). Similarly, in the GIB case the partners' strong relational capital, in particular their communication norms of openness and transparency, had helped them to develop their shared understanding of GIBs’ systems (see link between relational dimension and cognitive dimension in Figure 1). According to our respondents, this knowledge of each other's operations (cognitive dimension) was significant for reducing internal uncertainty, because it served to establish the principles behind service delivery in a manner that was going to be beneficial for both sides (see link between cognitive dimension and internal uncertainty in Figure 1).

In both cases, frequent on-going communication via telephone conferences and mutual visits by managers (structural dimension) allowed employees within the client and vendor firms to get to know the people they had been talking to and understand more about the business practices and challenges of both organizations (cognitive dimension). Our respondents used phrases such as 'people calling each other', 'people explaining to each other', 'people flying to India when needed' in order to emphasize the importance of communication processes and their role in generating cognitive social capital (see link between structural dimension and cognitive dimension in Figure 1).

In the LION-FDL case, a number of our respondents further mentioned the role of a boundary spanner, which can be regarded as part of the structural dimension of social capital, 
in the reduction of behavioral and internal uncertainty between the two organizations. A number of respondents acknowledged that his role was critical in bringing the two organizations together and bridging the gaps in the understanding of each other's objectives, expectations and business processes, thus creating cognitive social capital (see link between structural dimension and cognitive dimension in Figure 1). Thereby, this boundary spanner was able to ensure effective service delivery, thus reducing internal uncertainty (see link between cognitive dimension and internal uncertainty in Figure 1).

In both case studies, the behavioral uncertainty between the two outsourcing partners appeared to be relatively low. The relational dimension of social capital that existed between the client and vendor organizations was illustrated to be particularly significant for behavioral uncertainty. In both cases, a number of our respondents indicated the importance of strong informal relationships (relational dimension) for creating a sense of reliability between the outsourcing partners. Informal communications and working practices created a bond between the two organizations and a climate of collaboration that reduced behavioral uncertainty (see link between relational dimension and behavioral uncertainty in Figure 1) and therefore the expectation of opportunistic behavior. Furthermore, the history of co-operation between client and vendor firms prior to signing the outsourcing contract had created trust and therefore reduced the expectation of opportunistic behavior on behalf of the vendor, which can be described as 'business familiarity' in the sense of Gefen et al. (2008). The clients were co-operating efficiently with the vendors, and the vendors had proved their trustworthiness by demonstrating a reliable and professional attitude. Frequent interactions and visits (structural dimension) had helped to develop such trusting relationships as well as shared communication norms (relational dimension) between the partners (see link between structural dimension and relational dimension in Figure 1). 
In sum, the creation of social capital between the client and supplier organizations contributed significantly to the reduction of internal uncertainty (LION case) and behavioral uncertainty (both cases) in the outsourcing arrangement, and thereby decreased the likelihood of opportunistic behavior on behalf of the vendors. We were able to designate the differential influence of the three social capital dimensions on specific types of uncertainty. We found a strong association between the cognitive dimension with internal uncertainty, and of the relational dimension with behavioral uncertainty. The structural dimension (in our case frequent communication and visits), played a role as the basis for developing cognitive and relational social capital.

Social capital did not affect environmental uncertainty directly, which is in line with our expectations. However, it has to be noted that social capital influenced the degree to which environmental uncertainty could entail opportunistic behavior. In our study, environmental uncertainty did not instigate opportunistic behavior, and this was because social capital had reduced internal and behavioral uncertainty to a level where vendor and supplier did not behave opportunistically, despite the uncertain environmental conditions.

\section{Theoretical contributions}

Our results reinforce the view that the theory of transaction costs alone is limited to fully account for the complex phenomenon of outsourcing, as suggested by Lacity et al. (2011). By demonstrating the important role of social capital for reducing uncertainty and thereby opportunistic behavior, we substantiate the argument that the neglect of the social context within which transactions take place significantly constrains explanations of how opportunistic behavior is elicited and how it can potentially be managed.

An analysis that takes a TCE perspective alone focuses on the significance of complex contracts or contracts with a large number of detailed clauses (Reurer \& Arino, 2007), as tools 
that safeguard against opportunistic behavior. The threat of the imposition of penalties and other accountabilities created as a result of legal obligations are regarded as the primary deterrents of opportunistic behavior. In this frame, TCE takes a rather coercive perspective on the mitigation of opportunistic behavior. In other words, this TCE approach assumes that vendors behave in a desirable way for the outsourcing venture not because they perceive attractive opportunities for collaboration, partnership and expansion, but because they are forced to do so.

Our case findings, however, reveal that the vendors of the arrangements under investigation had numerous opportunities (resulting from environmental uncertainty and/or internal uncertainty) to behave opportunistically, but did not do so. While TCE theory was useful in the identification of situations where the vendors could have behaved opportunistically, we found that this theory could not adequately explain why this did not actually happen. Accordingly, our analysis demonstrates that a combination of TCE with the theory of social capital unveils a range of avenues of how opportunistic behavior can be reduced deliberately. In this frame, we found that the dimensions of social capital, including frequent and close interactions, a shared understanding and vision, as well as trust and strong communication norms, reduced internal and behavioral uncertainty and therefore mitigated the risk for opportunistic behavior.

Our research also provides contributions to social capital theory. Researchers have regarded social capital as a resource that leads to several benefits (e.g. Coleman, 1988, Inkpen \& Tsang, 2005; Payne et al., 2011; Reagans \& Evily, 2003), but they have not paid attention to its role in reducing internal and behavioral uncertainty and opportunistic behavior. To some extent, these effects resonate with the 'solidarity' benefits mentioned by Adler and Kwon (2002), who explain that strong social norms and beliefs (as part of the relational dimension) lead to solidarity within a social network, because they encourage members to comply with a 
group's rules, which in turn reduces the need for formal controls (2002: 29), which can be explained in terms of uncertainty reduction. It is clear that for network members, solidarity creates a degree of certainty about other network members' behavior. This may be most apparent and most important in settings of high environmental and internal uncertainty, such as ours. In such settings, strong social ties can create solidarity which reduces uncertainties about other network members' behaviors. This, in turn, will diminish the need for formal, contractual control of these behaviors. More specifically, our findings demonstrate that a shared vision (cognitive dimension), trust, and shared communication norms (relational dimension) motivated members of both firms to spend effort in achieving shared goals, to act in a reliable and trustworthy manner, and to expect the other partner to do the same, even in the absence of formal controls. In this sense, it created solidarity between the partners, which yielded some certainty that other members of the arrangements would not act in an opportunistic manner. By combining TCE and social capital theory, we were however able to go beyond the notion of solidarity and its role in uncertainty reduction. We were able to explain in detail how each of the three dimensions of social capital affected different types of uncertainty and thereby mitigated the risk of opportunistic behavior in outsourcing relationships.

\section{Practical implications}

Our findings have important practical implications. According to our results, investment in mechanisms of social capital can contribute significantly to the reduction of uncertainty between the outsourcing partners and therefore mitigate the possibility for opportunistic behavior. Visits of managers from the client to the supplier, and vice versa, have been found to have a particularly significant impact on the creation of cognitive and relational social capital. These visits facilitate a better understanding between people and enable them to better 
understand the workings and processes between both organizations. In this way, managers gain important knowledge on how they can improve their processes and work together in a way that will satisfy the expectations of both sides.

While increasing the social interactions among managers is important, we suggest that building social capital requires more than establishing social ties. In our view, it requires nurturing the motivation to sustain and cultivate the relationship. We found the role of boundary spanners to be particularly significant in this direction. Key individuals who have a very good understanding of the processes and business on both sides can create a sense of reliability for the customer, and also facilitate the relationship between the two organizations. Vendor organizations should therefore pay particular consideration to the role of boundary spanners.

\section{Limitations and further research}

The main limitation of this study is that it focused on two case studies and has limited power to provide statistically generalizable results (Yin, 2009). The primary objective of this research, however, was to generate an in-depth assessment of the social context of the outsourcing transactions under investigation and, in this frame, conduct a thorough examination of a vendor's opportunistic behavior and the role of uncertainty. We therefore decided to use an in-depth qualitative case study approach in order to yield more profound and richer insights into the phenomenon. Future research could use the elements of our model - social capital dimensions, types of uncertainty, and opportunistic behavior - as variables for a quantitative survey to test the model and assess the generalizability of our findings across a broad range of companies.

To gain a broader view, it is also necessary to conduct further qualitative, in-depth research on the role of social capital for opportunistic behavior in other settings. To 
consolidate our model, it would be useful to investigate contrasting cases where social capital is weak, for example through infrequent communication or significant relational conflicts.

Another limitation of our research is that our examination focused on opportunistic behavior on behalf of the vendor. Opportunistic behavior on behalf of the client, in turn, is a relatively under-researched area. It would therefore be significant for future research to provide a more in-depth consideration of the factors that lead to the engagement of opportunistic behavior on behalf of the client, as well as directions for their deterrence.

In our study, we focused on opportunistic behavior in conjunction with the existence of uncertainty in the outsourcing venture. Future research could explore the role of social capital mechanisms in conjunction with other factors that influence opportunistic behavior from a TCE point of view, such as transaction frequency, asset specificity and 'small numbers of suppliers'. Researchers could address the impact of social capital on opportunistic behavior in the context of different types of relationship specific investments, i.e. human, temporal, dedicated, site, procedural or physical investments (see Williamson, 1985) and address their potential to mitigate opportunistic behavior. Social capital mechanisms may also be relevant when there is a 'small number' of suppliers in the market, and therefore the relationship aspects of the arrangement become more prominent. Last but not least, future research could explore the role of social capital in the context of multi-sourcing arrangements, especially in co-ordinating the activity and mitigating the potential for opportunistic behavior across a set of vendors.

\section{CONCLUSION}

In this paper, we have made a first important step in combining the theories of TCE and social capital to provide a more detailed view of mechanisms by which opportunistic behavior in outsourcing relationships can be prevented. Whilst TCE theory highlights the role of asset 
specificity and uncertainty for opportunistic actions, social capital theory sheds light on how, very specifically, the structural, cognitive, and relational dimension of social capital can mitigate the impact of different types of uncertainty.

Our qualitative methodology allowed us to provide rich descriptions of the levels of uncertainty surrounding the transaction and the prevailing social capital mechanisms between the outsourcing partners. We further validate that the social context within which transactions take place is crucial, and the occurrence of opportunistic behavior should be studied in conjunction with this context. While TCE takes a rather coercive perspective on the deterrence of opportunistic behavior, the theory of social capital reveals a range of more deliberate avenues in this respect. When social capital is strong, transaction partners are more likely to refrain from opportunistic behavior by their own volition. In our case, strong social capital motivated members of both firms to behave in a reliable and trustworthy manner, even in the absence of formal controls. This mutual solidarity created a sense of certainty that other network members of the outsourcing arrangement would not behave in an opportunistic manner.

Our research therefore suggests that the theory of transaction costs, while providing a useful frame for thought on sourcing decisions, is not adequate for accommodating opportunistic behavior in outsourcing transactions in a comprehensive manner. Instead, the theory of social capital should be used as a complement to the transaction costs theorization to facilitate stronger accounts on outsourcing considerations. 


\section{REFERENCES:}

Adler, P.S. and Kwon, S.-W. (2002). Social Capital: Prospects for a New Concept, Academy of Management Review 27(1): 17-40.

Ang, S. and Cummings, L. (1997). Strategic Response to Institutional Influences on Information Systems Outsourcing, Organization Science 8(3): 235-256.

Artz, K. W. and Brush, T. H. (2000). Asset Specificity, Uncertainty and Relational Norms: An Examination of Coordination Costs, Journal of Economic Behavior and Organization 41: 337-62.

Aubert, B.A., Rivard, S. and Patry, M. (2004). A transaction cost model of IT outsourcing, Information and Management 41: 921-932.

Bahli, B. and Rivard, S. (2013). Cost Escalation in Information Technology Outsourcing: A Moderated Mediation Study, Decision Support Systems 56: 37-47.

Barthelemy, J. (2003). The Hard and Soft Sides of IT Outsourcing Management, European Management Journal 21(5): 539-548.

Barthelemy, J. and Quelin, B.V. (2006), Complexity of Outsourcing Contracts and Ex Post Transaction Costs: An Empirical Investigation, Journal of Management Studies, 43(8):17751797.

Benbasat, I. Goldstein, D. and Mead, M. (1987). The Case Research Strategy in Studies of Information Systems, MIS Quarterly 11(3): 368-387.

Borgatti, S. and Foster, P. (2003). The Network Paradigm in Organizational Research: A Review and Typology, Journal of Management 29(6): 991-1013.

Cannon, J and Perreuault, W. (1999). Buyer-seller relationships in business markets, Journal of Marketing Research 36(4): 439-460.

Cataldo, and Herbsleb (2008). Communication networks in geographically distributed software development, in Proceedings of the 2008 ACM conference on Computer supported cooperative work; New York, NY, USA: ACM. 579-588.

Chen, A. Bharadwaj, A. (2009). An empirical analysis of contract structures in IT outsourcing, Information Systems Research 20 (4): 484-506.

Coleman, J.S. (1988). Social capital in the creation of human capital, American Journal of Sociology 94: S95-S120.

Computer Weekly (2013). Investigating IT Outsourcing, available at: http://www.computerweekly.com/blogs/outsourcing/2013/08/it-outsourcing-in-banksdriven-by-customer-focus.html, site last visited in June, 2013. 
Cummings, J.N. (2011). Geography is alive and well in virtual teams, Communications of the ACM 54: 24-26.

De Vita, G. Tekaya, A. and Wang, C. (2010). Asset Specificity's Impact on Outsourcing Relationship Performance: A Disaggregated Analysis by Buyer-Supplier Asset Specificity Dimensions, Journal of Business Research 63: 657-666.

Dibbern, J., Winkler, J. and Heinzl., A. (2008). Explaining variations in client extra costs between software projects offshored to India, MIS Quarterly 32(2): 333-366.

Eisenhardt, K. (1989). Building Theories from Case Study Research, The Academy of Management Review 14(4): 532-550.

Equaterra (2010). Governance Best Practice Masterclass, available at: http://www.equaterra.com/_filelib/filecabinet/newsletters/equaterra_masterclass__optimising_outsourcing_governance_-_june_2010.pdf, site last visited in June, 2010.

Gefen, D., Wyss, S., and Lichtenstein, Y. (2008). Business Familiarity as Risk Mitigation in Software Development Outsourcing Contracts, MIS Quarterly 32(3): 531-542.

Geyskens, I. Steenkamp, J.B. and Kumar, N. (2006). Make, Buy, or Ally: A Transaction Cost Theory Meta-Analysis, Academy of Management Journal 49(3): 519-543.

Ghoshal, S. and Moran, P. (1996). Bad for Practice: A Critic of the Transaction Cost Theory, Academy of Management Review 21: 13-47.

Goo, J. Nam, K. and Kishore, R. (2009). The Role of Service Level Agreements in Relational Management of Information Technology Outsourcing: An Empirical Study, MIS Quarterly 33: 119-145.

Gooroochurn, N. and Hanley, A. (2007). A Tale of Two Literatures: Transaction Costs and Property Rights in Innovation Outsourcing, Research Policy 36(10): 1483-1495.

Gopal, A. and Koka, B. (2012). The Assymetric Benefits of Relational Flexibility: Evidence from Software Development Outsourcing, MIS Quarterly 36: 553-576.

Granovetter, M. (1985). Economic action and social structure: The problem of embeddedness, American Journal of Sociology 91(3): 481-510.

Grover, V. Cheon, M.J. and Teng. JTC. (1996). The Effect of Service Quality and Partnership on the outsourcing of Information Systems Functions, Journal of Management Information Systems, 12(4):89-116.

Gulati, R. and Nickerson, J.A. (2008). Interorganizational Trust, Governance Choice, and Exchange Performance, Organization Science 19: 688-708.

Herbsleb, J.D. and Mockus, A. (2003). An empirical study of speed and communication in globally-distributed software development, IEEE Transactions of software Engineering 29(6): 481-494. 
Hsu, M.-J., Ju, T.L., Yen, Ch.-H. and Chang, Ch.-M. (2007). Knowledge sharing behaviour in virtual communities: the relationship between trust, self-efficacy, and outcome expectations, International Journal of Human-Computer Studies 65(2): 153-169.

Inkpen, A.C. and Tsang, E.W.K. (2005). Social capital, networks, and knowledge transfer, Academy of Management Review 30(1): 146-165.

Jap, S. and Anderson, E. (2003). Safeguarding Interorganizational Performance and Continuity Under Ex Post Opportunism, Management Science 49(12):1684-1701.

Karimi-Alaghehband, F., Rivard, S., Wu, S., and Goyette, S. (2011). An Assessment of the Use of Transaction Cost Theory in Information Technology Outsourcing, Journal of Strategic Information Systems 20(2): 125-138.

Kelly, S. and Noonan, C. (2008). Anxiety and psychological security in offshoring relationships: the role and development of trust as emotional commitment, Journal of Information Technology 23: 232-248.

Kern T. and Willcocks, L. (2002). Exploring Relationships in Information Technology Outsourcing: The Interaction Approach, European Journal of Information Systems 11(1): 3-19.

King, N. (2004). Using templates in the thematic analysis of texts. In: Essential guide to qualitative methods in organizational research, Cassell, C. \& Symon, G. (eds.), pp. 256-270. Sage, Thousand Oaks, CA.

Kirsch, L.J. (2004). Deploying Common Systems Globally: The Dynamics of Control, Information Systems Research, 15(4): 374-395.

Klein, S. (1989). A transaction cost explanation of vertical control in international markets, Journal of the Academy of Marking Science, 17: 253-260.

Koopmans, T. (1957). Three Essays on the State of Economic Science. McGraw-Hill, New York.

Lacity, M., Khan, S. Yan, A. and Willcocks, L. (2010). A Review of the IT Outsourcing Empirical Literature and Future Research Directions, Journal of Information Technology 25,4: 395-433.

Lacity, M. and Willcocks, L. (2009). Information Systems and Outsourcing: Studies in Theory and Practice. London: Palgrave.

Lacity, M. and Willcocks, L. and Khan, S. (2011). Beyond transaction cost economics: towards an endogenous theory of information technology outsourcing, Journal of strategic information systems 20(2): 139-157.

Lee, J.N. Minh, Huynh, M. and Hirschheim, R. (2008). An Integrative Model of Trust on IT Outsourcing: Examining a Bilateral Perspective, Information Systems Frontiers 10: 145-163. 
Lumineau, F. and Quelin, B. (2011). An Empirical Investigation of Inter-organizational Opportunism and Contracting Mechanisms, Strategic Organization 10(1): 55-84.

Macher, J. T. and Richman, B. D. (2008). Transaction Cost Economics: An Assessment of Empirical Research in the Social Sciences, Business and Politics 10: 1-63.

Mani, D. Barua, A. and Whinston. A. (2012). An Empirical Analysis of the Contractual and Information Structures of Business Process Outsourcing Relationships, Information Systems Research 23:3180634.

McIvor, R. (2008). What is the Right Outsourcing Strategy for your Process, European Management Journal 26:24-34.

Mercer (2010). Global Governance Survey 2009/2010: Highlights, available at: http://uk.mercer.com/summary.htm?siteLanguage $=1008$ \&idContent $=1378055$, site last visited June 2013

Miranda, S.M. and Kim, Y. (2006). Professionalism versus political contexts: institutional mitigation and the transaction cost heuristic in information systems outsourcing, MIS Quarterly 30(3):725-753.

Mohr, J.J. and Speckman, R.E. (1994). Characteristics of Partnership Success: Partnership Attributes, Communication Behavior, and Conflict Resolution Techniques, Strategic Management Journal, 15: 135-152.

Møller-Larsen, M., Manning, S., \& Pedersen, T. (2013). Uncovering the hidden costs of offshoring: The interplay of complexity, organizational design, and experience. Strategic Management Journal, 34: 533-552.

Myers, M.D. (1994). Dialectical Hermeneutics: A Theoretical Framework for the Implementation of Information Systems, Information Systems Journal 5(1):51-70.

Nahapiet, J. and Ghoshal, S. (1998). Social capital, intellectual capital and the organizational advantage, Academy of Management Review 23(2):242-266.

Newell, S. and Swan, J. (2000). Trust and inter-organizational Networking, Human Relations (53:10), 287-328.

Nyaga, G. Whipple, J. and Lynch, D. (2010). Examining Supply Chain Relationships: Do Buyer and Supplier Perspectives on Collaborative Relationships Differ?, Journal of Operations Management, 28:101-114.

Ouchi, W. (1980). Markets, bureaucracies, and clans, Administrative Science Quarterly 25, 1:129-141.

Parkhe, A. (1993). Strategic Alliances Structuring: a Game-theoretic and Transaction Cost Examination of Interfirm Cooperation, Academy of Management Journal, 36(4):794-829. 
Payne, G.T., Moore, C.B., Griffis, S.E. and Autry, C.W. (2011). 'Multilevel challenges and opportunities in social capital research,' Journal of Management (37:2), pp. 491-520.

Perrow, C. (1986). Complex organizations: A critical essay. New York: Random House.

Poppo, L. and Zenger, T.R. (2002). Do Formal Contracts and Relational Governance Function as Substitutes or Complements, Strategic Management Journal, 23, 707-725.

Rawlinson, T. (2011). “UK IT Service Provider Performance and Satisfaction Study Findings - the Financial Services Sector Perspective', available at: http://blog.equaterra.com/2011/01/uk-it-service-provider-performance-and-satisfactionstudy-findings-\%E2\%80\%93-the-financial-services-sector-perspective/, site last visited December 2013

Reagans, R. and Evily, B. (2003). Network structure and knowledge transfer: the effects of cohesion and range, Administrative Science Quarterly (48):240-267.

Reurer, J. and Arino, A. (2007). Strategic alliance contracts: Dimensions and determinants of contractual complexity, Strategic Management Journal 28: 313-330.

Rindfleisch, A. and Heide, J. (1997). Transaction Cost Analysis: Past, Present, and Future Applications, Information Systems Journal 61(4):30-54.

Rindfleisch, A. Kersi, A. Bercovitz, J. Brown, J. Cannon, J. Carson, S. Ghosh, M. Helper, S. Robertson, D. Wathne, K. (2010). Transaction Costs, Opportunism, and Governance: Contextual Considerations and Future Research Opportunities, Marketing Letters 21:211-222.

Rottman, J.W. (2008) Successful knowledge transfer within offshore supplier networks: a case study exploring social capital in strategic alliances, Journal of Information Technology 23: 31-43.

Sahay, S. Nicholson, B. and Krishna, S. (2003). Global IT Outsourcing - Software Development Across Borders, Cambridge University Press, UK.

Saunders, C., Gebelt, M. and Hu, Q. (1997). Achieving Success in Information Systems Outsourcing, California Management Review 39(2):63-79.

Stringfellow, A. Teagarden, M.B., \& Nie, W. (2008). Invisible costs in offshoring services work. Journal of Operations Management, 26:164-179.

Subasingha, M. Sedera, D. and Murphy, Glen D. (2012). Multi-level knowledge transfer in software development outsourcing projects : the agency theory view, 33rd International Conference on Information Systems, Orlando.

Thouin, M. Hoffman, J. and Ford, E. (2009). IT outsourcing and firm-level performance: A transaction cost perspective, Information \& Management 46:463-469. 
Tiwana, A. and Bush, A. (2007) A Comparison of Transaction Cost, Agency, and Knowledge-Based Predictors of IT Outsourcing Decisions: A US-Japan Cross-Cultural Field Study, Journal of Management Information Systems 24(1):259-300.

Tompkins, J. Simonson, S. Tompkins, W. and Upchurch, B. (2006). Creating and Outsourcing Relationship, Supply Chain Management Review 10(2):52-58.

Uzzi, B. (1996). The Sources and Consequences of Embeddeness for the Economic Performance of Organizations: The Network Effect, American Sociological Review 61(4):674-698.

Van den Hoof, Ridder, D.J. and Aukema, E. (2004). Exploring the Eagerness to Share Knowledge: The Role of Social Capital and ICT in Knowledge Sharing, in Huysman, M. and Wulf, V. (2004). Social Capital and Information Technology, MIT Press, London.

Walker, G. and Weber, D. (1984). A transaction cost approach to make-or-buy decisions, Administrative Science Quarterly 29(3):373-391.

Wathne, K. H. and Heide, J. B. (2000). Opportunism in Interfirm Relationships: Forms, Outcomes, and Solutions, Journal of Marketing 64(4): 36-51.

Westner, M. and Strahringer, S. (2010). Determinants of success in IS offshoring projects: Results from an empirical study on German companies, Information \& Management 47(5): 291-299.

Willcocks, L., Cullen, S. and Craig, A. (2011). The Outsourcing Enterprise: From Cost Management to Collaborative Innovation, London: Palgrave.

Williamson O.E. (1981). The Modern Corporation: Origins, Evolution, Attributes, Journal of Economic Literature, 19(4):1537-1568.

Williamson O.E. (1985). The Economic Institutions of Capitalism, Free Press.

Williamson O.E. (1993). Opportunism and its critics. Managerial and Decision Economics, 14: 97-107.

Williamson, O.E. (1998). Transaction Cost Economics: How it Works; Where it is Headed, De Economist, 146:23-58.

Yin, R. (2009). Case Study Research: Design and Methods, Sage, London.

Zazac, E. J., \& Olsen, C. P. (1993). From transactional cost to transactional value analysis: Implications for the study of interorganizational strategies. Journal of Management Studies 30(1): 131-145.

Zahedia, F. Bansalb, G. and Ischec, J. (2010). Success Factors in Cooperative Online Marketplaces: Trust as the Social Capital and Value Generator in Vendors-Exchange Relationships, Journal of Organizational Computing and Electronic Commerce 20:4. 
Zimmermann, A. (2011). Interpersonal relationships in transnational, virtual teams - towards a configurational perspective, International Journal of Management Reviews, 13(1): 5978.

Zimmermann, A. and Ravishankar, M.N. (2014). Knowledge transfer in IT offshoring relationships: The roles of social capital, efficacy and outcome expectations, Information Systems Journal 24(2): 167-202. 
Figure 1. Social capital, uncertainty, and opportunistic behavior in the outsourcing partnership

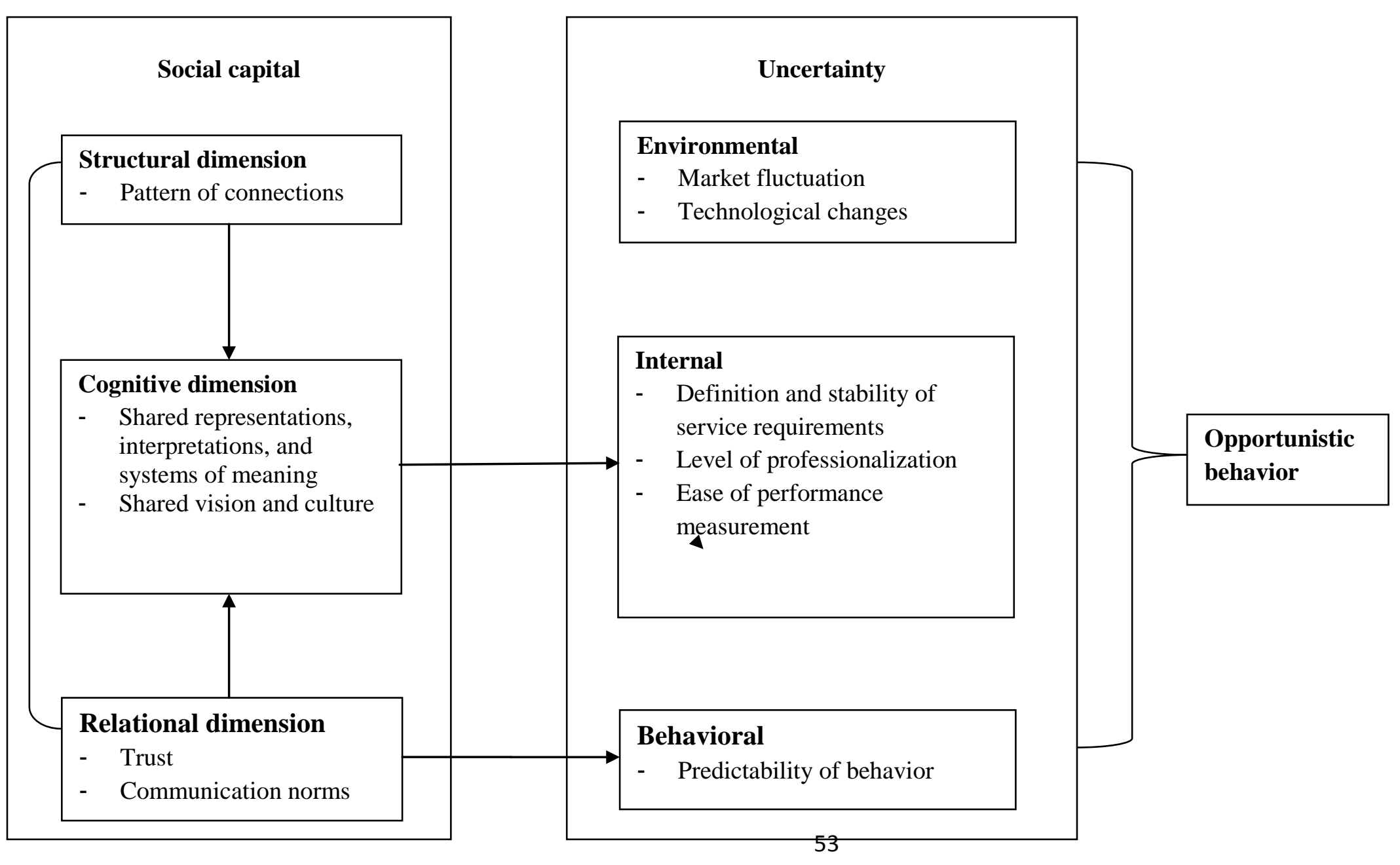


Table 1. Research participants from LION and FDL

\begin{tabular}{|l|l|}
\hline \multicolumn{2}{|c|}{ LION case study } \\
\hline $\begin{array}{l}\text { Research participants from } \\
\text { LION }\end{array}$ & Role \\
\hline RP1 & Director \\
\hline RP2 & Lawyer \\
\hline RP3 & Business manager \\
\hline RP4 & Demand manager \\
\hline RP5 & Contract manger \\
\hline RP6 & Contract manager \\
\hline RP7 & Senior manager \\
\hline RP8 & Service manager \\
\hline
\end{tabular}

\begin{tabular}{|l|l|}
\hline $\begin{array}{l}\text { Research participants from } \\
\text { FDL }\end{array}$ & Role \\
\hline RP9 & Contract manager \\
\hline RP10 & Account manager \\
\hline RP11 & Consultant \\
\hline RP12 & Program manager \\
\hline
\end{tabular}


Table 2. Research participants from GIB and PV

\begin{tabular}{|l|l|}
\hline \multicolumn{2}{|c|}{ GIB case study } \\
\hline $\begin{array}{l}\text { Research participants } \\
\text { from GIB }\end{array}$ & Role \\
\hline RP13 & $\begin{array}{l}\text { Vendor } \\
\text { decisions/Relationship } \\
\text { management }\end{array}$ \\
\hline $\begin{array}{l}\text { RP14 (seven } \\
\text { conversations) }\end{array}$ & Director of risk \\
\hline RP15 (two conversations) & Lawyer \\
\hline RP16 & $\begin{array}{l}\text { Investment Banking IT } \\
\text { Sourcing and Vendor } \\
\text { Management of IT } \\
\text { portfolio }\end{array}$ \\
\hline RP17 & Lawyer \\
\hline RP18 & Consultant \\
\hline RP19 & $\begin{array}{l}\text { Global technology } \\
\text { outsourcing vendor } \\
\text { management }\end{array}$ \\
\hline RP20 & $\begin{array}{l}\text { Senior manager in } \\
\text { operations }\end{array}$ \\
\hline RP21 & X-RAY product manager \\
\hline RP22 & Client solutions partner \\
\hline \hline $\begin{array}{l}\text { Research participants } \\
\text { from PV }\end{array}$ & Role \\
\hline RP23 & $\begin{array}{l}\text { Head of integrated } \\
\text { services delivery }\end{array}$ \\
\hline RP24 & Global account manager \\
\hline RP25 (five conversations) & $\begin{array}{l}\text { X-RAY Global } \\
\text { transformation manager }\end{array}$ \\
\hline RP26 & $\begin{array}{l}\text { X-RAY European program } \\
\text { manager }\end{array}$ \\
\hline
\end{tabular}

